\title{
Análise da co-utilização do resíduo do beneficiamento do caulim e serragem de granito para produção de blocos e telhas cerâmicos
}

\section{(Analysis of the use of kaolin processing waste and granite sawing waste together for the production of ceramic bricks and roof tiles)}

\author{
R. R. Menezes, R. R. de Almeida, L. N. L. Santana, G. A. Neves, H. L. Lira, H. C. Ferreira \\ Unidade Acadêmica de Engenharia de Materiais, Centro de Ciências e Tecnologia, \\ Universidade Federal de Campina Grande \\ Av. Aprígio Veloso 882, Bodocongó, Campina Grande, PB 58109970 \\ gelmires@dema.ufcg.edu.br,heber@dema.ufcg.edu.br
}

\begin{abstract}
Resumo
O volume de resíduos gerado pela mineração e o beneficiamento mineral vêm se intensificando a cada dia, em virtude do aumento da demanda causado pelo crescimento da economia mundial. As indústrias do beneficiamento do caulim e da serragem do granito são importantes segmentos econômicos do Estado da Paraíba, entretanto produzem enormes quantidades de resíduos. Assim, este trabalho tem por objetivo caracterizar os resíduos do beneficiamento do caulim e da serragem do granito e avaliar a viabilidade de sua co-utilização para produção de blocos e telhas cerâmicos. Os resíduos foram caracterizados através da determinação de sua composição química e mineralógica, pelo uso de difração de raios X e análise térmica diferencial e gravimétrica, distribuição e tamanho de partículas e análise morfológica por microscopia eletrônica de varredura. Foram formuladas composições contendo os resíduos e confeccionados corpos de prova por extrusão. Os corpos de prova foram queimados e em seguida determinou-se sua absorção de água e módulo de ruptura à flexão. Pode-se observar que o resíduo do caulim é constituído por caulinita, mica e quartzo, que o resíduo de granito é constituído por quartzo, mica, albita e calcita e, que os resíduos apresentam distribuições granulométricas significativamente diferentes. Concluiu-se também que é possível a incorporação de até $50 \%$ de resíduo em formulações para produção de blocos e telhas cerâmicas e que a co-utilização do resíduo de granito e de caulim possibilita obter propriedades físicas superiores às observadas nos corpos de prova com incorporação de apenas resíduo de caulim.
\end{abstract}

Palavras-chave: resíduo, reciclagem, caulim, granito, blocos e telhas cerâmicos.

\begin{abstract}
The amount of wastes generated by the miner and mineral processing industries has increasing day by day due to the high demand cause by the global economy grow up. The processing kaolin ad sawing granite industries are important economic segments in the state of Paraiba, but generate high amounts of wastes. This work has as aim the characterization of the kaolin processing waste and granite sawing waste and the evaluation of their use together for the production of bricks and roof tiles. The wastes were characterized by chemical composition determination, X-ray diffraction, differential thermal and gravimetric analyses, particle size distribution determination, and morphological analysis by electronic scanning microscopy. Several formulations were prepared and samples bodies were prepared by extrusion. The sample bodies were fired at 800,900 and $1000^{\circ} \mathrm{C}$. Fired samples were characterized in terms of water absorption and mechanical strength. The results showed that the kaolin waste is composed by kaolinite, mica and quartz and that the granite waste is composed by quartz, mica, albite and calcite, and that, the wastes have significantly distinct particles size distributions. It could also be concluded that are possible incorporations of up to $50 \%$ of wastes in formulation for the production of ceramic bricks and roof tiles, and that, the use of the kaolin waste and granite waste together provide better physical properties than those observed in samples bodies with incorporations of only kaolin waste.
\end{abstract}

Keywords: waste, recycling, kaolin, granite, ceramic bricks and roof tiles.

\section{INTRODUÇÃO}

Em todo o mundo milhões de toneladas de resíduos inorgânicos são produzidos a cada dia nas atividades de mineração e beneficiamento mineral. Tradicionalmente esses resíduos são descartados em aterros e, muito comumente, são jogados diretamente no meio ambiente, sem qualquer processo de tratamento ou imobilização. Todavia, alternativas de reciclagem e/ou reutilização devem ser investigadas e, sempre que possível, implementadas [1,2]. A abordagem ambiental mais recente, objetiva, exatamente, o desenvolvimento sustentável, com a minimização do descarte dos materiais oriundos das atividades industriais [3].

A inserção dos resíduos num ciclo produtivo deve 
representar uma opção de recuperação alternativa desses materiais, que é interessante tanto no aspecto ambiental, como no econômico. Nesse sentido, a indústria cerâmica vem demonstrando grande potencial para a reutilização de resíduos inorgânicos [4].

Cerâmicas tradicionais como telhas, blocos erevestimento cerâmicos geralmente apresentam grande variação de composição devido ao largo intervalo de composições das argilas utilizadas como matérias-primas para sua fabricação, o que possibilita uma grande tolerância para a incorporação de grandes quantidades de resíduos inorgânicos. O potencial de incorporação de resíduos nas formulações de cerâmicas tradicionais, aliado às elevadas quantidades de recursos naturais consumidos a cada dia por esse segmento industrial, ressalta a importância da reutilização de resíduos como matérias-primas cerâmicas alternativas, racionalizando o uso dos recursos naturais [5-7]. A diminuição gradual na abundância dos recursos minerais causou a recente tendência em substituir minerais por fontes alternativas de matériasprimas, que estão disponíveis em abundância, como os resíduos industriais e da mineração $[8,9]$, o que está em acordo com uma das mais importantes e difíceis tarefas para o futuro e o desenvolvimento sustentável, a minimização do consumo das matérias-primas tradicionais [4].

A incorporação de resíduos de várias atividades industriais em produtos cerâmicos é também uma alternativa tecnológica para reduzir os impactos ambientais e efeitos danosos à saúde humana, causados pelo descarte indiscriminado de resíduos na natureza $[10,11]$.

A indústria da mineração e beneficiamento de caulim do Estado da Paraíba produz milhares de toneladas de caulim por ano, sendo um importante segmento econômico em várias regiões do Estado. Entretanto, a indústria do caulim também produz uma elevada quantidade de resíduo. Dois tipos de resíduos são gerados por essa indústria; um "grosso" (com tamanho de partículas $>200 \mu \mathrm{m}$ ), que é constituído basicamente por quartzo e é gerado na primeira etapa do beneficiamento do caulim, e um "fino" que é oriundo da etapa de purificação do caulim através de processos de separação a úmido do caulim da ganga do minério. Esses resíduos são geralmente descartados a céu aberto e em leitos e várzeas de riachos e rios, causando danos à fauna, à flora e à saúde da população.

A região Nordeste também possui uma grande concentração de indústrias de beneficiamento de granito, responsáveis pela comercialização de milhares de toneladas de peças beneficiadas por ano e com forte importância econômica em vários Estados. No entanto, essas empresas são responsáveis pela liberação de centenas de toneladas de resíduo no meio ambiente. O resíduo da serragem de granito consiste numa "lama" com elevados teores de $\mathrm{SiO}_{2}, \mathrm{Al}_{2} \mathrm{O}_{3}$, $\mathrm{Fe}_{2} \mathrm{O}_{3}$ e $\mathrm{CaO}$, formada pelo pó oriundo da serragem e por partículas de granalha e cal que são utilizados durante o processo. A lama do beneficiamento do granito é em geral descartada em córregos, ravinas e lagos, havendo a formação de grandes depósitos a céu aberto. A lama da serragem enquanto fluída afoga plantas e animais e deprecia o solo; quando seca, sua poeira inspirada é danosa à saúde [5, 7].

Nos últimos anos várias pesquisas tem sido dedicadas ao estudo da reutilização de resíduos da indústria da mineração e beneficiamento de minérios, como matérias-primas alternativas para a indústria de cerâmicas tradicionais [3, 5, 7,12-19]. Grande parte deles dedicou-se ao estudo do resíduo da serragem de granito e evidenciaram o potencial e importância desse resíduo como matéria-prima alternativa para a produção de revestimentos, blocos e telhas cerâmicos.

Trabalhos anteriores [20, 21] demonstraram o potencial do uso do resíduo do beneficiamento do caulim como matéria-prima para a produção de corpos cerâmicos porosos e revestimentos. Entretanto, nenhum trabalho abordou a utilização de formulações cerâmicas contendo resíduo de caulim e resíduo de granito, que explorassem as características argilosas do resíduo de caulim e fundentes do resíduo de granito para a confecção de blocos e tijolos cerâmicos. Assim, esse trabalho tem por objetivo caracterizar os resíduos do beneficiamento do caulim e da serragem do granito e avaliar a viabilidade de sua co-utilização para produção de blocos e telhas cerâmicos.

\section{MATERIAIS E MÉTODOS}

Foram utilizados os seguintes materiais: resíduo de caulim, proveniente da segunda etapa de beneficiamento (cedido pela empresa Caulisa Indústria S/A, Juazeirinho, $\mathrm{PB}$ ); resíduo da serragem do granito (cedido pela empresa Fuji S.A. - Mármores e Granitos, Campina Grande, PB) e argila vermelha. A argila vermelha foi estudada anteriormente [22] e é constituída por caulinita, quartzo e mica, apresenta uma larga distribuição de tamanho de partículas $\left(D_{10}=2 \mu \mathrm{m}\right.$ e $\mathrm{D}_{90}=60 \mu \mathrm{m}$ ), com tamanho médio de partícula de $8,22 \mu \mathrm{m}$ e é utilizada para produção de blocos e telhas pela Cerâmica Espírito Santo, PB.

Os resíduos de caulim e granito foram caracterizados

Tabela I - Massas cerâmicas com resíduo de caulim e de granito.

[Table I-Ceramic formulations with kaolin and granite wastes.]

\begin{tabular}{lccccccccc}
\hline Matérias-Primas & \multicolumn{8}{c}{ Composição (\% em peso) } \\
& M & M5 & M10 & M15 & M20 & M25 & M30 & M40 & M50 \\
\hline Argila & 100 & 95 & 90 & 85 & 80 & 75 & 70 & 60 & 50 \\
Resíduo de Granito & 0 & 2,5 & 5 & 7,5 & 10 & 12,5 & 15 & 20 & 25 \\
Resíduo de Caulim & 0 & 2,5 & 5 & 7,5 & 10 & 12,5 & 15 & 20 & 25 \\
\hline
\end{tabular}


através da determinação da sua composição química por fluorescência de raios X (Shimadzu EDX-90), difração de raios X (Siemens D5005), análises térmica diferencial (ATD) e termogravimétrica (TG) (BP Engenharia, RB3000), determinação da distribuição do tamanho de partícula (Cilas, 1064LD) e microscopia eletrônica de varredura (MEV) (Leica, S440). Para os ensaios de caracterização os resíduos foram cominuídos em almofariz e passados em peneira com abertura de $74 \mu \mathrm{m}$ (ABNT No 200), à exceção do ensaio de determinação da distribuição granulométrica, para o qual os resíduos foram passados em peneira com abertura de 300 $\mu \mathrm{m}($ ABNT No 80$)$.

Os resíduos foram secos a $100{ }^{\circ} \mathrm{C}$, desaglomerados em moinho de bolas e peneirados através de peneira com abertura de $300 \mu \mathrm{m}$ (ABNT $\mathrm{N}^{\circ}$ 80). Em seguida foram preparadas formulações por meio da mistura a seco em moinho de bolas por $2 \mathrm{~h}$ dos resíduos de granito e caulim e da argila vermelha. A Tabela I apresenta as composições estudadas. Após mistura em moinho de bolas, as formulações foram novamente passadas por peneira com abertura de 300 $\mu \mathrm{m}$ (ABNT $\mathrm{N}^{\circ}$ 80). Foi feita a determinação dos limites de plasticidade das massas, segundo metodologia da NBR 6459 [23] e NBR 7180 [24]. Em seguida, foram confeccionados corpos de prova de $200 \mathrm{~mm}$ x $20 \mathrm{~mm}$ x $5 \mathrm{~mm}$ por extrusão, que foram queimados a 800,900 e $1000{ }^{\circ} \mathrm{C}$.

Os corpos de prova queimados foram submetidos a ensaio de caracterização física, com determinação da absorção de água e módulo de ruptura a flexão (com velocidade de aplicação de carga de $0,5 \mathrm{~mm} / \mathrm{min}$ )

\section{RESULTADOS E DISCUSSÃO}

A Tabela II apresenta a composição química dos resíduos estudados. O resíduo de caulim contém $\mathrm{SiO}_{2}$ e $\mathrm{Al}_{2} \mathrm{O}_{3}$ como principais constituintes e $\mathrm{Fe}_{2} \mathrm{O}_{3}, \mathrm{~K}_{2} \mathrm{O}$ e $\mathrm{TiO}_{2}$ em menores proporções. Observa-se uma elevada quantidade de fundentes (particularmente $\mathrm{K}_{2} \mathrm{O}$ ) no resíduo. $\mathrm{O}$ resíduo de granito também contem $\mathrm{SiO}_{2}$ e $\mathrm{Al}_{2} \mathrm{O}_{3}$ como principais constituintes. No entanto, a proporção de fundentes $\left(\mathrm{Fe}_{2} \mathrm{O}_{3}\right.$, $\mathrm{Na}_{2} \mathrm{O}$ e $\mathrm{K}_{2} \mathrm{O}$ ) é significativamente superior à observada no resíduo de caulim. O elevado teor de $\mathrm{Fe}_{2} \mathrm{O}_{3}$ e $\mathrm{CaO}$ no resíduo de granito é devido a utilização de granalha e cal como agentes abrasivos e lubrificantes, respectivamente, durante o processo de serragem.

A Fig. 1 apresenta os padrões de difração de raios $\mathrm{X}$ dos resíduos. Pode-se observar que o resíduo de caulim apresenta caulinita, quartzo e mica como fases cristalinas, enquanto que as fases cristalinas observadas no resíduo de granito foram quartzo, mica, albita (feldspato sódico) e calcita (carbonato de cálcio). Pode-se observar que o $\mathrm{K}_{2} \mathrm{O}$ presente na composição química dos resíduos é oriundo basicamente de mica, enquanto que o $\mathrm{Na}_{2} \mathrm{O}$ observado na composição do resíduo de granito é oriundo de feldspato sódico. O potássio oriundo da mica provavelmente não terá uma acentuada ação fundente nas temperaturas de queima utilizadas nesse trabalho; entretanto, o $\mathrm{Na}_{2} \mathrm{O}$, oriundo do feldspato, pode favorecer a densificação das formulações, mesmo nas baixas temperaturas utilizadas nesse trabalho, a qual pode se intensificar com a formação de eutéticos dos óxidos fundentes.

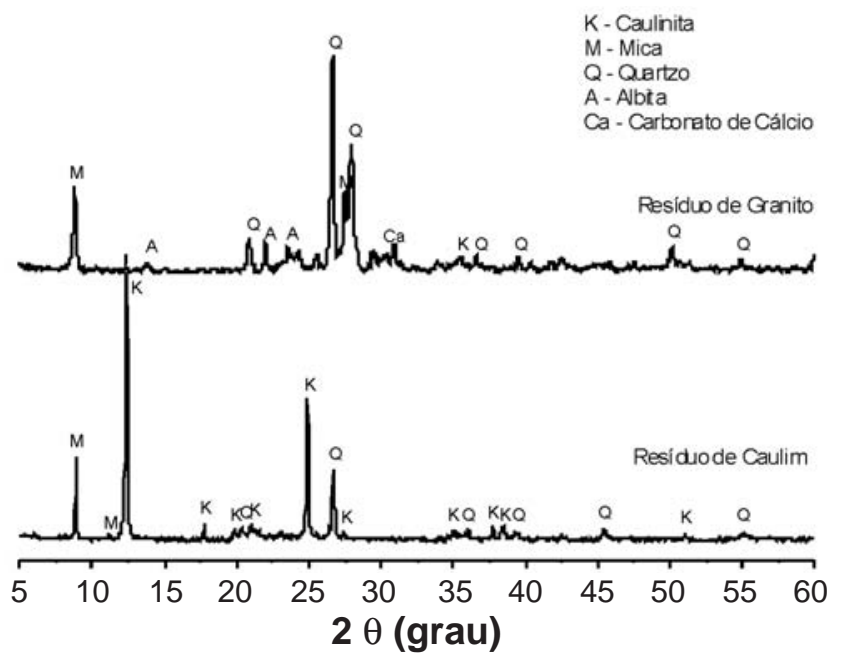

Figura 1: Padrões de difração de raios $\mathrm{X}$ do resíduo de granito e do resíduo de caulim.

[Figure 1: X-ray diffraction patterns of the granite and kaolin wastes.]

A Fig. 2 apresenta as curvas de análises térmica diferencial (ATD), termogravimétrica (TG) e a diferencial da termogravimétrica (DTG) dos resíduos. A curva de ATD do resíduo de caulim apresenta um pico endotérmico por volta de $580{ }^{\circ} \mathrm{C}$, provavelmente associado à desidroxilação da caulinita e um pico exotérmico em torno de $980{ }^{\circ} \mathrm{C}$, provavelmente relacionado à nucleação de mulita. Através das curvas de TG e DTG do resíduo de caulim verifica-se perda de massa entre 450 e $600{ }^{\circ} \mathrm{C}$, entre 700 e $760{ }^{\circ} \mathrm{C}$ e entre 780 e $860^{\circ} \mathrm{C}$, associadas provavelmente à desidroxilação da caulinita e mica e a recristalização da mica respectivamente, havendo

Tabela II - Composição química do resíduo de granito e do resíduo de caulim.

[Table II - Chemical composition of the granite and kaolin wastes.]

\begin{tabular}{lccccccccc}
\hline Matérias-Primas & $\mathrm{SiO}_{2}$ & $\mathrm{Al}_{2} \mathrm{O}_{3}$ & $\mathrm{Fe}_{2} \mathrm{O}_{3}$ & $\mathrm{~K}_{2} \mathrm{O}$ & $\mathrm{TiO}_{2}$ & $\mathrm{CaO}$ & $\mathrm{MgO}$ & $\mathrm{Na}_{2} \mathrm{O}$ & $\mathrm{PF}^{\mathrm{a}}$ \\
\hline Resíduo de Granito & 62,77 & 14,38 & 6,58 & 3,78 & - & 6,28 & - & 3,52 & 2,68 \\
Resíduo de Caulim & 52,68 & 33,57 & 0,93 & 5,72 & 0,12 & - & - & - & 6,75 \\
\hline${ }^{a}$ Perda ao Fogo & & & & & & & & &
\end{tabular}



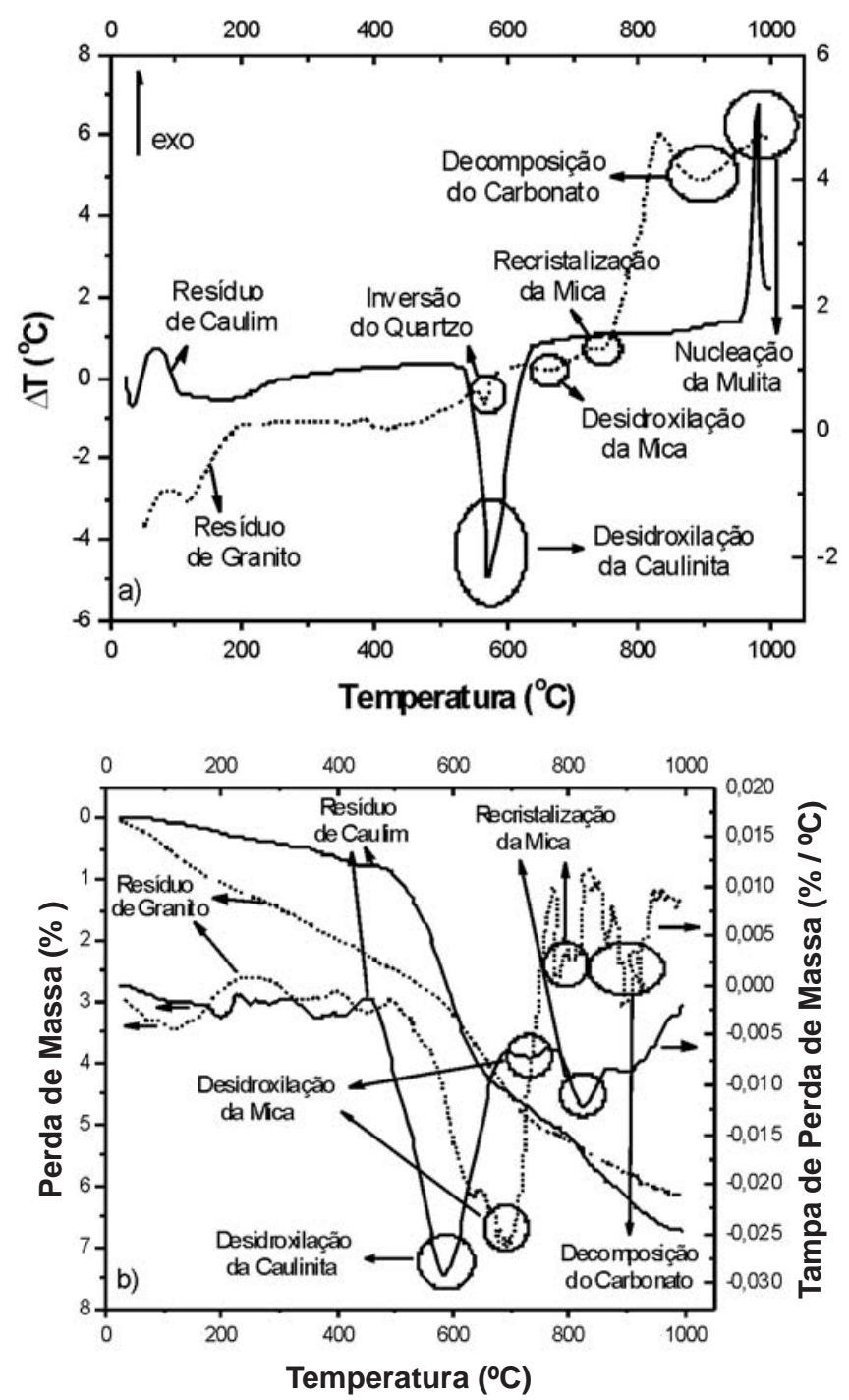

Figura 2: a) Análise térmica diferencial e b) termogravimétrica e diferencial termogravimétrica do resíduo de granito e do resíduo de caulim.

[Figure 2: Thermal differential (a), thermogravimetric and differential termogravimetric analysis of the granite and kaolin wastes.]

uma perda de massa total de aproximadamente 6,5\%. Na curva de ATD do resíduo de granito (Fig. 2) observa-se um pequeno pico endotérmico a aproximadamente $560{ }^{\circ} \mathrm{C}$, provavelmente associado a transformação alfa-beta do quartzo, picos endotérmicos a 660 e $760^{\circ} \mathrm{C}$ provavelmente relacionados a desidroxilação e recristalização da mica respectivamente e uma banda de aproximadamente 840 a $950{ }^{\circ} \mathrm{C}$, possivelmente relacionada à decomposição do carbonato. Nas curvas de TG e DTG verifica-se bandas de perda de massa relacionadas provavelmente a desidroxilação da mica, recristalização da mica e decomposição do carbonato.

A distribuição do tamanho de partículas dos resíduos estudados está na Fig. 3. O resíduo de caulim apresentou um tamanho médio de partícula de $54,4 \mu \mathrm{m}$ e uma faixa de tamanho de partículas larga, com $\mathrm{D}_{10}$ de $2 \mu \mathrm{m}$ e $\mathrm{D}_{90}$ de 130 $\mu \mathrm{m}$. O resíduo de granito apresentou um tamanho médio de partícula de 24,5 $\mu \mathrm{m}$ e uma faixa de distribuição de tamanho de partículas significativamente mais estreita que a observada no resíduo de caulim, $\mathrm{D}_{10}$ de $2 \mu \mathrm{m}$ e $\mathrm{D}_{90}$ de $60 \mu \mathrm{m}$.
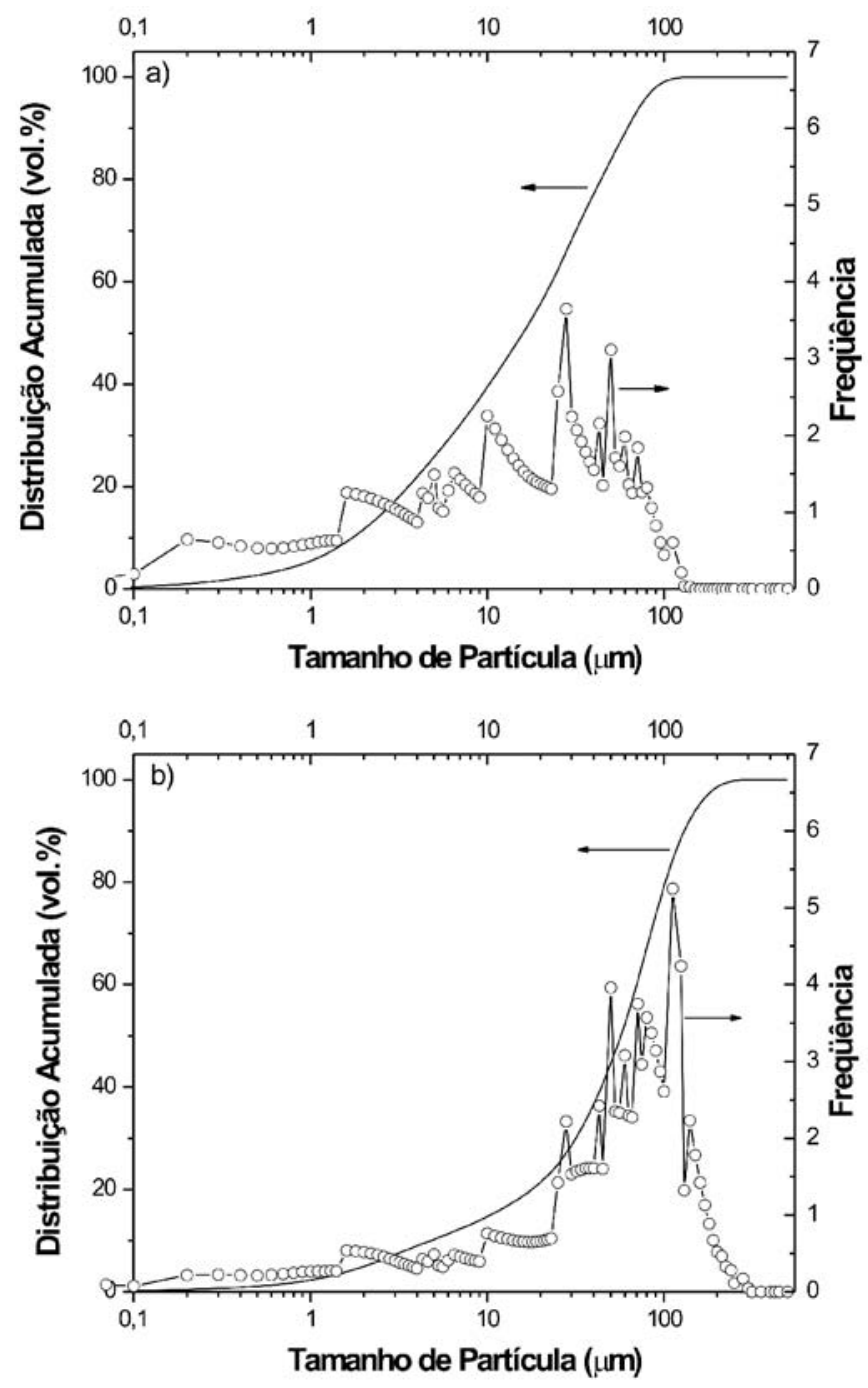

Figura 3: Distribuição do tamanho de partículas a) do resíduo de granito e b) do resíduo de caulim.

[Figure 3: Particle size distribution of the a) granite and b) kaolin wastes.]

A morfologia dos pós dos resíduos pode ser observada na Fig. 4. Verifica-se que o resíduo de caulim apresenta partículas finas e grossas em um largo intervalo de dimensões. As partículas maiores apresentam forma irregular, com cantos agudos, parecendo ser partículas de quartzo, enquanto as partículas finas estão presentes na forma de aglomerados, o que indica que a pequena fração argila (partículas $<2 \mu \mathrm{m}$ ) observada na curva de distribuição de tamanho de partículas (Fig. 3) pode ser devido ao fato dos argilo-minerais estarem presentes na forma de grandes aglomerados. O pó do resíduo de granito apresenta partículas maiores com morfologia irregular e superfície arredondada e algumas outras com cantos angulosos. Observa-se uma maior quantidade de 

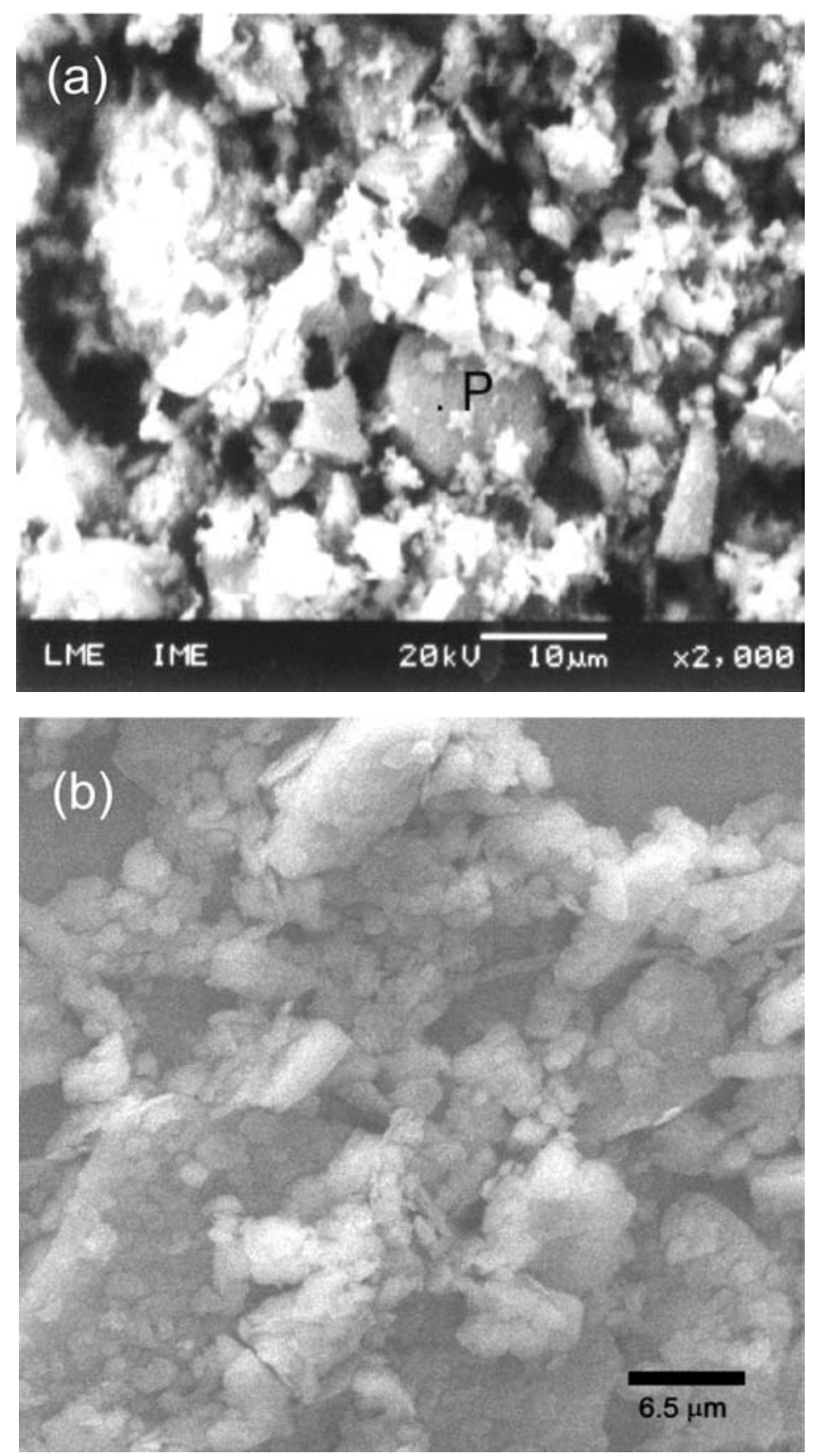

Figura 4: Micrografias obtidas em microscopia eletrônica de varredura: a) do resíduo de granito e b) do resíduo de caulim.

[Figure 4: SEM micrographs of a) granite waste and b) kaolin waste.]

partículas finas, comparativamente ao resíduo de caulim e uma menor proporção de aglomerados.

Com base na caracterização mineralógica, na distribuição do tamanho de partículas e na análise morfológica, observase que o resíduo de caulim apresenta partículas grandes, de até $200 \mu \mathrm{m}$ e a presença de elevada quantidade aglomerados.
Em trabalhos anteriores [20, 21] observou-se que a adição de grande quantidade de resíduos de caulim (acima de 15\%) em formulações cerâmicas dificultava o empacotamento dos corpos a verde e a densificação do produto final, o que está associado, provavelmente, às características granulométricas desse material. A dificuldade de empacotamento imposta pela incorporação do resíduo de caulim foi evidenciada também em estudo [22] que demonstrou que elevadas taxas de cisalhamento durante a homogeneização da massa e confecção dos corpos de prova possibilita diminuir as dificuldades de empacotamento oriundas dos aglomerados do resíduo, observando-se que a utilização do processo de extrusão para a conformação do produto favorecia a densificação, com relação a processos de prensagem uniaxial.

Analisando as características físicas de alguns outros resíduos de granito utilizados em trabalhos anteriores [5, $7,10]$ observou-se que seria possível utilizar o resíduo da serragem de granito de forma conjunta com o resíduo de caulim a fim de favorecer o empacotamento do sistema e a sua densificação, beneficiando-se das distribuições granulométricas conjuntas e da presença de uma maior quantidade de fundentes no resíduo de granito.

A Tabela III apresenta os limites de plasticidade das formulações estudadas. Pode-se observar que a incorporação dos resíduos de forma combinada permitiu adicionar grande quantidade de resíduo $(50 \%)$, sem, entretanto, uma diminuição do limite de plasticidade da massa final. Ocorreu uma diminuição em torno de apenas 16\% mesmo com a adição de 50\% de resíduo. Dados da literatura [19, 25-27] indicam limites de plasticidade entre 18 e 30\% para processamento de cerâmicas vermelhas por extrusão. Assim, observa-se que a combinação dos resíduos possibilita processar facilmente as massas por processo de extrusão.

A Fig. 5 apresenta a absorção de água dos corpos de prova confeccionados a partir das formulações contendo resíduo de caulim e granito, após queima a 800, 900 e 1000 ${ }^{\circ} \mathrm{C}$. Também são apresentados dados obtidos [22] a partir de formulações que utilizaram a mesma proporção de resíduo e que sofreram o mesmo processamento, entretanto contendo apenas o resíduo de caulim como incorporação. Esses dados visam facilitar a comparação e evidenciar o efeito do resíduo de granito nas propriedades finais do corpo cerâmico.

Com base na Fig. 5 pode-se observar um aumento da absorção de água dos corpos de prova queimados com a elevação da quantidade de resíduo. Esse aumento variou de 40 a $45 \%$ nos corpos de prova contendo incorporações de apenas resíduo de caulim, dependendo da temperatura de

Tabela III - Limite de plasticidade das massas com resíduos de granito e de caulim.

[Table III - Plasticity limit of formulations with granite and kaolin wastes.]

\begin{tabular}{lllllllll}
\hline & \multicolumn{7}{c}{ Formulações } \\
\cline { 2 - 9 } & M & M5 & M10 & M15 & M20 & M30 & M40 & M50 \\
\hline Limite de Plasticidade & 23,9 & 23,7 & 22,7 & 21,7 & 21,3 & 20,8 & 20,2 & 19,9 \\
\hline
\end{tabular}




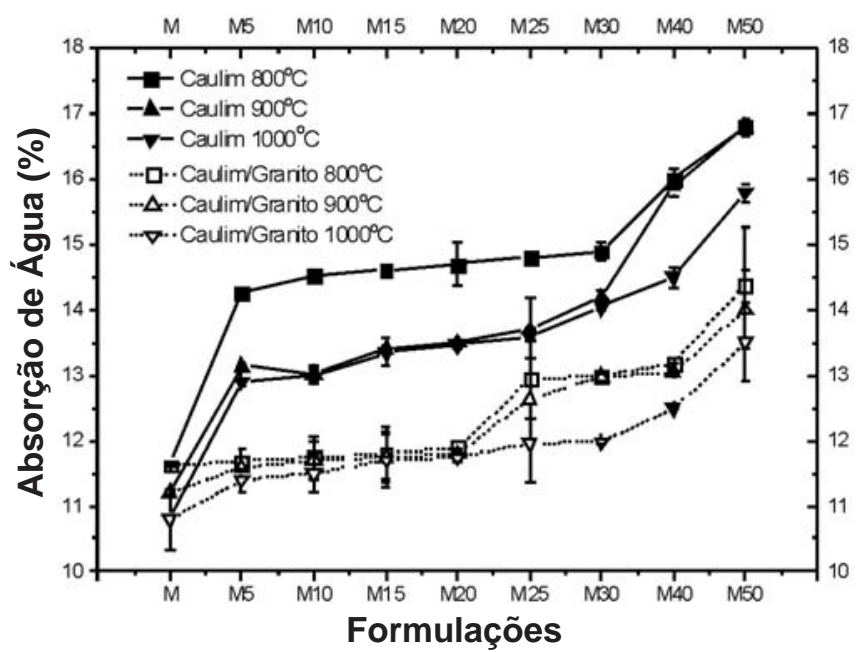

Figura 5: Absorção de água dos corpos de prova após queima. [Figure 5: Water absorption of the fired sample bodies.]

queima, enquanto que nos corpos de prova contendo resíduo de granito e caulim o aumento da absorção variou de 19 a 26\%. A utilização conjunta dos resíduos permite adições de até $20 \%$ de resíduo sem alterações significativas da absorção de água, independentemente da temperatura de queima, o que é bem distinto do observado nos corpos de prova contendo apenas o resíduo do caulim. Além disso, com a queima a 1000 ${ }^{\circ} \mathrm{C}$, verifica-se que é possível a incorporação de resíduos em até 30\% sem grande aumento da absorção de água, ficando inferior a $11 \%$. Verifica-se que o aumento da temperatura provoca a diminuição da absorção de água dos corpos de prova tanto das formulações contendo apenas resíduo de caulim, como daquelas contendo os dois tipos de resíduos. Entretanto, verifica-se que a utilização conjunta dos resíduos possibilitou obter corpos de prova que após queima mesmo em baixas temperaturas, como $800^{\circ} \mathrm{C}$, apresentam absorção inferior à dos corpos de prova contendo apenas resíduo de caulim após queima a $1000{ }^{\circ} \mathrm{C}$. Segundo normalização [28] para blocos cerâmicos de alvenaria todas as formulações apresentam valores de absorção dentro da faixa especificada (8 a $25 \%)$.

A Fig. 6 apresenta o módulo de ruptura dos corpos de prova confeccionados a partir das formulações contendo resíduo de caulim e granito, após queima a 800, 900 e $1000{ }^{\circ} \mathrm{C}$. Da mesma forma que na Fig. 5, também são apresentados dados obtidos [22] a partir de formulações que utilizaram a mesma proporção de resíduo e que sofreram o mesmo processamento, entretanto contendo apenas o resíduo de caulim como incorporação, a fim de facilitar comparações. Observa-se uma diminuição do módulo de ruptura com o aumento da quantidade de resíduo incorporado às formulações em todas as temperaturas utilizadas no estudo. Pode-se observar uma diferença no comportamento de decréscimo do módulo de ruptura dos corpos de prova contendo resíduo de granito e caulim daquele dos corpos de prova contendo apenas resíduo de caulim. Nos corpos de prova contendo apenas resíduo de caulim observa-se uma diminuição acentuada

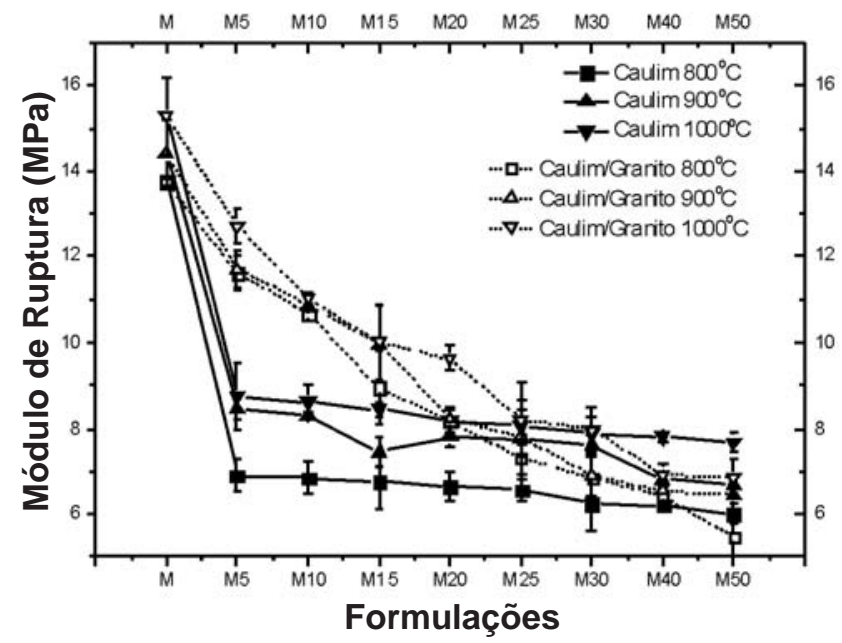

Figura 6: Módulo de ruptura à flexão dos corpos de prova após queima.

[Figure 6: Modulus of rupture of the fired sample bodies.]

do módulo mesmo com pequenas adições de resíduo, como $5 \%$, e que, a incorporação de maiores quantidades não altera significativamente o módulo de ruptura dos corpos de prova. Já nos corpos de prova contendo resíduos de granito e caulim, verifica-se um decréscimo mais suave do módulo de ruptura com a adição e aumento da quantidade de resíduo incorporado. Esse decréscimo mais suave possibilita que se atinjam maiores módulos de ruptura nos corpos de prova contendo resíduos de granito e caulim, quando se trabalha com quantidades de até $20 \%$ de resíduo. Em quantidades de até $20 \%$ a queima a $800{ }^{\circ} \mathrm{C}$ dos corpos de prova contendo os dois tipos de resíduos propicia módulo de ruptura igual ao obtido nos corpos de prova contendo apenas resíduo de caulim com a queima a $1000{ }^{\circ} \mathrm{C}$, o que evidencia que a co-utilização dos resíduos, em quantidades de até $20 \%$, permite, além de aumentar a resistência dos corpos de prova, utilizar menores temperaturas de queima. Em quantidades superiores a $25 \%$ de resíduo incorporado, com o desvio padrão não há diferenças nos módulos de ruptura dos corpos de prova contendo resíduo de granito e caulim com relação aos que contém apenas resíduo de caulim. Apesar da menor absorção de água, os corpos de prova contendo os dois tipos de resíduos, quando de adições acima de $25 \%$ não apresentaram melhores propriedades mecânicas. Esse comportamento está sendo analisado, entretanto ainda não se tem uma explicação para esse comportamento, já que, apesar da maior fração de material argiloso no resíduo de caulim (em relação ao resíduo de granito), a temperatura de queima foi muito baixa para se atribuir esse comportamento mecânico semelhante (apesar da diferença de absorção) apenas a uma maior formação de mulita. Com relação a temperatura de queima, não houve aumenta significativo do módulo de ruptura dos corpos de prova contendo resíduo de granito e caulim, após queima a 800,900 e $1000{ }^{\circ} \mathrm{C}$. Nos corpos de prova contendo apenas resíduo de caulim observase um aumento mais distinto do módulo de ruptura com o aumento da temperatura de queima. 
As formulações contendo até $50 \%$ de resíduos podem ser utilizadas em cerâmica vermelha. As formulações com até $40 \%$ de resíduos podem ser utilizadas para a produção de blocos maciços, furados e telhas (módulo de ruptura mínimo de 2,0, 5,5 e 6,5 $\mathrm{MPa}$, respectivamente), mesmo após queima a $800{ }^{\circ} \mathrm{C}[25,29]$. E as formulações contendo $50 \%$ de resíduos podem ser utilizadas para a produção de telhas após queima a $1000{ }^{\circ} \mathrm{C}$. Após queima a 800 e $900{ }^{\circ} \mathrm{C}$, essa formulação pode ser utilizada para a produção de tijolos maciços e furados.

Assim, verifica-se que a combinação dos dois tipos de resíduos possibilita obter tanto melhores propriedades de trabalhabilidade das massas cerâmicas para o processamento por extrusão, mesmo com elevadas quantidades de resíduos, como também melhores propriedades físicas quando se trabalha com quantidade de até $20 \%$ de resíduo. Anecessidade de re-utilização dos vários resíduos gerados pela sociedade moderna, visando um desenvolvimento sustentável com economia dos recursos naturais e preservação do meio ambiente, evidencia a necessidade da busca de alternativas para aumentar a absorção de resíduos por parte da indústria cerâmica. A co-utilização de resíduos com propriedades físicas e mineralógicas distintas vem mostrando permitir o aumento das quantidade incorporadas nas massas cerâmicas $[1,8,12,18,30,31]$. Pode-se observar nesse trabalho que essa metodologia de abordagem possibilita re-utilizar grandes volumes de resíduos, sem alterar o ciclo produtivo, obtendose produtos com características comerciais semelhantes aos produzidos com matérias-primas virgens. Trabalhos em desenvolvimento, a serem publicados, já evidenciam a possibilidade de incorporação de quantidades ainda maiores de resíduos, utilizando-se a abordagem de combinação de resíduos.

\section{CONCLUSÕES}

O resíduo de caulim é constituído por caulinita, quartzo e mica e o resíduo de granito é composto por quartzo, mica, albita e calcita;

O resíduo de caulim apresenta uma larga distribuição granulométrica, com tamanho médio de partícula $54 \mu \mathrm{m}$ e o resíduo de granito apresenta uma distribuição mais estreita de tamanho de partícula, com tamanho médio de partícula $24,5 \mu \mathrm{m}$;

A absorção de água dos corpos de prova contendo resíduos aumenta com a elevação da quantidade de resíduos; entretanto, os valores são inferiores aos obtidos utilizandose apenas resíduo de caulim como incorporação aos corpos de prova;

O módulo de ruptura dos corpos de prova diminui com o aumento da quantidade de resíduos incorporados; no entanto, a combinação dos resíduos possibilita atingir valores superiores ao obtidos com a utilização de apenas o resíduo de caulim;

A co-utilização dos resíduo de granito e caulim possibilita atingir valores de módulo de ruptura após queima a $800{ }^{\circ} \mathrm{C}$, somente atingidos pelos corpos de prova contendo apenas resíduo de caulim, após queima a $1000{ }^{\circ} \mathrm{C}$;

É possível a incorporação de grandes quantidades de resíduos, de até $50 \%$, em formulações para produção de tijolos maciços e furados e telhas.

\section{AGRADECIMENTOS}

Ao CNPq (471414/04-9) e à FAPESQ/MCT/CNPq (003/03 e 001/06) pelo apoio financeiro.

\section{REFERÊNCIAS}

[1] F. Raupp-Pereira, D. Hotza, A. M. Segadães, J. A. Labrincha, Ceram. Int. 32, 2 (2006) 173.

[2] D. U. Tulyaganov, S. M. H. Olhero, M. J. Ribeiro, J. M. F. Ferreira, J. A. Labrincha, J. Mater. Synth. Proc. 10, 6 (2002) 311.

[3] L. P. de F. Souza, H. S. Mansur, J. Mater. Process. Technol. 145 (2004) 14.

[4] F. Andreola, L. Barbieri, A. Corradi, I. Lancellotti, T. Manfredini, J. Eur. Ceram. Soc. 22 (2002) 1457.

[5] R. R. Menezes, H. S. Ferreira, G. A. Neves, H. C. Ferreira, Cerâmica 48 (2002) 92.

[6] P. Torres, H. R. Fernandes, S. Agathopoulos, D. U. Tulyaganov, J. M. F. Ferreira, J. Eur. Ceram. Soc. 24 (2004) 3177.

[7] R. R. Menezes, H. S. Ferreira, G. A. Neves, H. L. Lira, H. C. Ferreira, J. Eur. Ceram. Soc. 25 (2005) 1149.

[8] K. Dana, J. Dey, S. K. Das, Ceram. Int. 31 (2005) 147152.

[9] R. R. Menezes, G. A. Neves, H. C. Ferreira, Rev. Bras. Eng. Agr. Amb. 6, 2 (2002) 303.

[10] E. Ozel, S. Turan, S. Çoruh, O. N. Ergun, Waste Management and Research 24 (2006) 125.

[11] D. G. Pinatti, R. A. Conte, M. C. Borlini, B. C. Santos, I. Oliveira, C. M. F. Vieira, S. N. Monteiro, J. Eur. Ceram. Soc. 26, 3 (2005) 305.

[12] M. S. Hernández-Crespo, J. Ma. Rincón, Ceram. Int. 27 (2001) 713.

[13] L. Catarino, J. Sousa, I. M. Martins, M. T. Vieira, M. M. Oliveira, J. Mater. Proc. Techn. 143-144 (2003) 843.

[14] C. M. F. Vieira, T. M. Soares, R. Sánchez, S. N. Monteiro, Mater. Sci. Eng. A 373 (2004) 115.

[15] S. N. Monteiro, L. A. Peçanha, C. M. F. Vieira, J. Eur. Ceram. Soc. 24 (2004) 115.

[16] J. M. S. Moreira, M. N. Freire, J. N. F. Holanda, Cerâmica 49, 312 (2004) 262.

[17] M. Campos, F. Velasco, M. A. Martínez, J. M. Torralba, J. Eur. Ceram. Soc. 24 (2004) 811.

[18] A. Olgun, Y. Erdogan, Y. Ayhan, B. Zeybek, Ceram. Int. 31 (2005) 153.

[19] J. M. S. Moreira, J. P. V. T. Manhães, J. N. F. Holanda, Cerâmica 51, 319 (2005) 180.

[20] R. R. Menezes, M. I. Brasileiro, D. H. S. Oliveira, G. A. Neves, H. L. Lira, H. C. Ferreira, Waste Management and Research, no prelo.

[21] R. R. Menezes, R. R. de Almeida, L. N. L. Santana, H. 
S. Ferreira, G. A. Neves, H. C. Ferreira, Revista Matéria 12 (2007) 226.

[22] R. R. Almeida, Diss. Mestrado, Universidade Federal de Campina Grande, PB (2006).

[23] Associação Brasileira de Normas Técnicas, Determinação do Limite de Liquidez: Método de Ensaio NBR 6459, Rio de Janeiro (1992).

[24] Associação Brasileira de Norms Técnicas, Determinação do Limite de Plasticidade: Método de Ensaio - NBR 7180, Rio de Janeiro (1992).

[25] P. Souza Santos, Ciência e Tecnologia de Argilas, $3^{a}$ Ed., Vol. 1, Edgard Blücher, S. Paulo (1992) 236.
[26] R. S. Macedo, Diss. Mestrado, Universidade Federal da Paraíba, Campina Grande, PB (1996).

[27] L. F. A. Campos, H. C. Ferreira, R. S. Macedo, Cerâmica, 45, 295 (1999) 140.

[28] Associação Brasileira de Normas Técnicas, Blocos Cerâmicos - NBR 7171, Rio de Janeiro (1992).

[29] I. L. Barzaghi, A. Salge, Cerâmica, 28, 151 (1982) 15. [30] A. M. Marabini, P. Plescia, D. Maccari, F. Burragato, M. Pelino, Int. J. Miner. Process., 53 (1998) 121.

[31] P. Pisciella, S. Crisucci, A. Karamanov, Waste Management 21 (2001) 1.

(Rec. 11/10/2006, Ac. 24/11/2006) 